\title{
LEITURA E FORMAÇÃO DO LEITOR
}

Josemilde Melo Barbosa da Hora ${ }^{1}$

Cátia Cristina Almeida de Jesus ${ }^{2}$

\section{RESUMO}

Este artigo tem como objetivo investigar como a formação de alunos leitores se associa ao papel do professor e de suas práticas pedagógicas, sendo assim, está sendo iniciado um estudo que analisa a formação do professor e a sua ação no ensino de leitura, textos e literatura. Este contexto problematiza e analisa a "Leitura e formação do leitor," e as inquietações que levaram a pesquisa deste tema tiveram como justificativa a utilização de textos literários e não literários e sua relação com a formação e trabalho do docente. As primeiras análises iniciais indicam para o uso da didática do docente na valorização e interação entre textos e alunos na construção de conhecimento. $O$ aluno deve compreender a leitura como fenômeno de comunicação que dá possibilidades para relacionar o seu contexto sociocultural, de maneira que, a leitura se torne significativa.

Palavras-chave: Formação Docente, Aluno Leitor, Conhecimento, Pesquisa, Humanização.

\section{ABSTRACT}

This article aims to investigate how the formation of readers students is associated with the role of the teacher and their teaching practices. That way, is being initiated a study that analyzes the formation of the teacher and his action in teaching reading, texts and literature. This context problematizes and analyses "Reading and reader training in public school, in elementary education $2 . "$ The concerns that lead to research this the me had as a justification the utilization of literary texts relation with the training and work of teacher. The first initials analyzes indicate to the teacher of didactics of use on the appreciation and interaction between texts and students in the construction of knowledge. The students hould understand reading as communication phenomenon that gives possibilities to relate their sociocultural context a manner that reading becomes significant.

Key Words: Teacher Education, Student Reader, Knowledge, Research, Humanize.

\section{INTRODUÇÃO}

O presente estudo aponta para necessidade de pesquisas sobre a relação entre a formação do professor e seu papel na mediação entre alunos e obras literárias e não literárias, até porque as várias leituras também deverão ser valorizadas no contexto escolar e fora dele, para que o aluno tenha conhecimentos de comparação

\footnotetext{
${ }^{1}$ Professora da Rede Pública e Particular de Ensino no Estado da Bahia. Formada em Letras, Língua Espanhola e suas Respectivas Literaturas pelo Centro Universitário Jorge Amado, Curso e Especialização em Psicopedagogia Clínica e Institucional pela Faculdade de Artes do Paraná, Curso de aperfeiçoamento de Novas Tecnologias na Educação pelo Centro cientifico Conhecer e participante do Curso de Formação Continuada Literatura Negra para Enegrecer os Modos do Saber pelo Centro de Estudos dos Povos-Afro-Índio-Americanos - CEPAIA (UNEB), turma 2013. Mestra em Ciências da Educação pela Facultad Interamericana de Ciências Sociales- FICS (2019).

2 Professora da rede pública de ensino. Formada em Licenciatura em Letras-Português/Inglês pela Faculdade de Tecnologia e Ciências - FTC (2010).Aperfeiçoamento em Comunicação Oral e Escrita na Língua Inglesa e Projetos Educacionais pelo CCAA (2012). Aperfeiçoamento em Educação para as Relações Étnicas Raciais pela UNILAB (2018). Pós-graduada em Metodologia do Ensino da Língua Portuguesa e Estrangeira pela UNINTER (2018). Mestra em Ciências da Educação pela Facultad Interamericana de Ciências Sociales- FICS (2019).
} 
e escolha de suas leituras, como também, saibam aplicar em diferentes situações de sua vida.

A inquietação para essa pesquisa tem como justificativa a necessidade de reflexão sobre as atuais formas do ponto de vista ou opiniões conceituais sobre o espaço escolar, tendo em vista um ensino que possa valorizar a formação do aluno em sua competência leitora, escrita e relacional, contudo a unidade escolar pode contribuir com o desenvolvimento da função básica da linguagem: a comunicação e a formação do pensamento generalizador.

Tendo como argumento, a importância da língua escrita em uma sociedade que valoriza a capacidade de representar a realidade e de comunicar-se através de um sistema de signos, o presente estudo foi realizado no contexto de uma escola pública e tem como foco a "Leitura e formação do leitor no fundamental II".

O ensino da escrita pode expressar suas ideias sobre o papel do professor na relação entre o texto e o leitor na construção de conhecimento, portanto este artigo tem como objetivo a formação de alunos leitores que pode se associar ao papel do professor e de suas práticas pedagógicas, dessa forma, está sendo estendido um estudo que relaciona a formação do professor e sua atuação no ensino de leitura e literatura, possibilitando a comunicação entre a linguagem e a escrita na escola e as ações no contexto sociocultural do aluno.

Como metodologia de trabalho utilizou-se observações, pesquisas bibliográficas em livros, revistas, artigos e documentos na internet com abordagens acerca da prática pedagógica que valoriza a leitura e a formação do leitor, com a apresentação de várias obras pela criatividade e versatilidade do docente, os estudos indicaram para o uso da didática docente na valorização e interação entre texto e aluno na construção de conhecimento.

As unidades escolares poderiam melhor contribuir para o desenvolvimento no contexto pós-moderno, em "territórios" de "transição", marcados por contextos de uma nova cartografia traduzidos na transitoriedade, no deslocamento, fluxo e aceleração de ações humanas. Ações essas, que não tem sido observada durante o ensino das disciplinas que a utilizam apenas como forma de currículo oficialmente proposto como forma de desenvolvimento. Com tudo, a utilização dos espaços escolares e dos tempos pedagógicos deve ser aproveitada de maneira que as ações decorram de uma boa formação de professores e de uma boa prática pedagógica no contexto escolar (LIMA, 2008). 
Os presentes ambientes sociais como: escolas, bibliotecas físicas e virtuais, centros urbanos, salas de leituras e outros, têm como objetivo despertar uma meta na organização e adequação dos códigos de linguagens, que tem como função principal proporcionar e estimular a comunicação da linguagem e da escrita entre os seres humanos para que a interação aconteça em sociedade.

Nesta acepção, a espécie humana possui uma habilidade singular: a capacidade de expressar-se "através da representação simbólica e de comunicar-se através de um sistema se signos realizados socialmente, que chamamos de língua, e que tem como efeito concreto nos diferentes atos comunicativos dos indivíduos" (COLOMER E CAMPS, 2002, p. 11).

Durante milhares de anos, os homens $\mathrm{e}$ as mulheres se comunicaram oralmente por Intermédio de desenhos, gestos, e pinturas, e ao longo da história, vários grupos sociais ampliaram suas possibilidades de comunicação com invenção de sistemas de Signos gráficos. As características desses novos códigos, tais como a estabilidade, a Comunicação em um tempo e um espaço não imediato ou a necessidade de uma aprendizagem específica para dominá-los, permitiram alcançar objetivos bastante diversos, desde o poder derivado da posse da palavra ou a segurança na transmissão de leis e ordens a terras distantes até a difusão em nossos conhecimentos.

Os sinais gráficos, no contexto atual são incumbidos de retratar esta relação de forma simbólica e de legitimar socialmente através de sua elaboração e propagação cultural, pois "a função do código de representação define aquilo que constitui a própria essência da língua escrita: um sistema de mediação entre o ser humano e a realidade por meio de sinais determinados" (COLOMER e CAMPS, 2002, p. 12).

Foram justamente as variações produzidas com tais finalidades que condicionaram o acesso a diferentes grupos sociais à língua escrita nas várias culturas e ao longo da história. Neste seguimento, a história apresenta a "habilidade de leitura e escrita como uma única realidade recente, entre os cinco mil e três mil últimos anos, segundo os critérios de definição que se adotem" (Ibid, 2002, p. 11-12), a leitura e a escrita do ponto de vista mais global de sua caracterização básica tem como instrumento de relação, o ser humano e o mundo, e no contexto contemporâneo, entre $o$ aluno leitor e o universo da comunicação. 


\section{A LEITURA, O SUJEITO E A INFORMAÇÃO}

A leitura proporciona ao leitor, o contato com seu significado e conhecimento de mundo, pois a leitura de um texto possibilita várias compreensões e interpretações, e através da leitura é constituída uma prática social, em que o sujeito, ao praticar o ato de ler, se transporta no processo de produção de sentidos, pois:

Ler pressupõe objetivos bem definidos. E esses objetivos são do próprio leitor, em cada uma das situações de leitura. São objetivos que vão se modificando à medida que lemos o texto. Por exemplo, quando pegamos uma revista para ler, num consultório médico, nosso objetivo pode ser o de apenas passar o tempo. Mas se descobrirmos um texto que indica como emagrecer sem parar de comer doces, aí o objetivo mudará (RANGEL \& ROJO, 2010, p.87).

$\mathrm{O}$ ato de ler pode ser concebido como o recurso pelo qual o indivíduo adentra o universo da cultura tornando-se um ser culto, racional e pensante. O significado de um texto é atribuído ao leitor que dá seus significados fazendo seus esquemas e baseando-se em suas informações, a leitura é responsável por contribuir, de forma significativa, na formação do indivíduo, estimulando-o a analisar a sociedade e seu cotidiano de modo particular ampliando, diversificando pensamentos, interpretações e compreensões sobre o mundo.

A leitura para se tornar agradável, é essencial que os ambientes sejam atrativos à sua aprendizagem, mas, acima de tudo, seja considerado e respeitado o nível sociocultural do leitor, até porque a leitura é a parte fundamental do saber, respalda nossas interpretações e nos promove a compreensão do outro e do mundo. De acordo com os Parâmetros Curriculares Nacionais:

A leitura é um processo no qual o leitor realiza um trabalho ativo de construção do significado do texto, a partir dos seus objetivos, do seu conhecimento sobre o assunto, sobre o autor, de tudo o que sabe sobre a língua: características do gênero, do portador, do sistema de escrita, etc (BRASIL, 2001, p. 53).

A leitura possibilita oportunidades para que se adquira meios, para se posicionar, questionar, dar opiniões de autores, refletir e formar seus próprios conceitos, dessa forma o professor como responsável da aprendizagem da leitura deverá elaborar estratégias significativas para que ocorra a formação do leitor, de forma consciente e efetiva de ler, pois só quem se relaciona com livros, será capaz de formar vários e bons leitores.

O professor deverá explicar para seus alunos que ler exercita o raciocínio, refina o seu conhecimento literário e que hoje em dia a leitura está presente em todos 
os lugares, para qualquer idade e diferentes classes sociais. E que pode- se fazer leituras de revistas, receitas, panfletos, outdoors, livros e outros, pois:

\begin{abstract}
O leitor contemporâneo, e a leitura, que hoje tem perfis diferentes daqueles com que idealmente as funções e papéis que a escola desempenha A escola sem dúvida trabalha com muitas das interpretações. Há o ler que posteriormente se detém na busca da informação. Há o ler cuja a natureza é puramente funcional. $E$ há o ler do produto ficcional - que deveria ser fonte de grande para os estudantes, mas que ao contrário, acaba por se construir em desagradável exercício de coerção, momento em que melhor o autoritarismo extemporaneidade que veem marcando boa parte do nosso tema escolar. E é nesse mesmo momento que se anulam as possibilidades de fruição da leitura (ROCCO, 2013, p. 41.).
\end{abstract}

Isso acontece porque a escola formal ignora a passagem do tempo e as várias visões do mundo, pois é importante que se entenda que a leitura pode ajudar a construir um caminho de grande interesse na aula de linguagem e o aluno não gosta de ler na escola, porque os textos e livros escolhidos pelo professor, não é do seu interesse, e assim não desperta nesse aluno o prazer de ler, pois:

E é nessa hora que tal escola perde qualquer razão, caminha sem rumo, às cegas, construindo, em vez de aprendizagem efetiva, um campo de tensões e conseguindo a triste façanha, sobretudo no que concerne à leitura, de abolir e castrar momentaneamente, entre os alunos, aquela atividade dialógica fundamental que define a natureza humana (lbid., 2013, p.42).

A leitura permite que o indivíduo pense o mundo através de livros e dessa forma a escola deve se preocupar em formar leitores para que ocorra o aprendizado real da leitura de modo que tenhamos alunos leitores e escritores conscientes de seu papel na sociedade e no mundo com intuito de tornar a vida mais prazerosa e agradável. $A$ leitura faz parte de todos os ambientes da sociedade, é através dela que o indivíduo pode ampliar seu conhecimento, aperfeiçoar a escrita, o vocabulário, entre outros aspectos, uma vez que:

A leitura passa a ser vista como um suporte propício para o dialogismo entre
autor e leitor, revelando uma nova visão extremamente rica, abrindo espaço
para subjetividade para expansão da criatividade, incentivando a leitura
coletiva e, consequentemente, a interação entre homens (RAIMUNDO, 2007,
p. 108).

A leitura leva o sujeito a ter senso crítico, bem como é importante entender que a leitura vai além da decifração do código escrito. Ao abordar a riqueza do ato de ler, pode-se afirma que "há três níveis de leitura que são: leitura sensorial, leitura emocional e leitura racional" (MARTINS, 1988, p. 37).

A leitura sensorial é direcionada a visão, audição, tato, paladar e olfato que são os sentidos do ser humano, ela refere-se a leitura inicial que se do mundo. A leitura emocional é a empatia e capacidade do cérebro ler ou compreender emoções de 
outras pessoas, desenvolvê-la permite experimentar sentimentos dos outros como se fosse nosso. E a leitura racional é baseada em fatos que geralmente vão constituir nossa bagagem cultural e movimenta as aptidões lógicas do leitor, a habilidade de avaliar o texto, espaçar suas partes, formando relações entre elas e outros textos, sintetizando as ideias do autor.

\section{A LEITURA E A FAMÍLIA}

O ambiente familiar deve incentivar a leitura porque senão a mesma acaba sendo vista como algo não interessante, já que só acontece em ambientes severos e de forma imposta. Entretanto, se o encorajamento à leitura acontecer no ambiente informal, especialmente no lar, iniciado desde que a criança ainda está no ventre, com cantigas de ninar, musiquinhas, histórias e contos fantásticos é mais presumível que o leitor tenha facilidade na compreensão dos textos. Pode-se afirmar que:

\footnotetext{
O leitor formado na família tem um perfil um pouco diferenciado daquele outro que teve o contato com a leitura apenas ao chegar na escola. $O$ leitor que se inicia no âmbito familiar demonstra mais facilidade em lidar com os signos compreende melhor o mundo no qual está inserido, além de desenvolver um senso crítico mais cedo, o que realmente importa na sociedade (VIEIRA, 2004, p. 6).
}

A família exerce um papel importante na formação de leitores, sendo assim, cabe a ela iniciar a leitura e formar leitores para toda vida, e dessa forma, tornar-se essencial, fornecendo boas condições e um ambiente acolhedor, prazeroso, para que o desenvolvimento da leitura seja importante para vida individual, social e cultural.

O indivíduo através do ato leitor desenvolve-se intelectualmente e espiritualmente, aprendendo e progredindo, já que é na família que o sujeito tem o primeiro contato com a leitura através de cantigas de ninar, histórias, ilustrações, e outras fontes que permitem entrar no mundo leitor. Sabe-se que os conhecimentos aprendidos na família, serão levados por toda vida, dito isto, ela é de grande importância no processo de leitura. Sobre essa ideia aborda-se que:

Sendo, portanto, uma miniatura da sociedade, a família se fortalece e como espaço privado de vivência, e é nesse interior do novo modelo familiar que o gosto pela leitura se intensifica. $O$ gosto pela leitura se constitui em atividade adequada a esse contexto de privacidade doméstica (Ibid, 2004, p.4).

A leitura não pode ser vista como obrigatória, mas proporcionar prazer, deleite, como também a cultura, o conhecimento, e o entusiasmo, tanto na família quanto na escola. $\mathrm{N}$ o ambiente familiar a leitura é muito mais relaxante, poque, o sujeito tem todo tempo do mundo para criar, representar, imaginar e assim passar a admirar a 
leitura com a ajuda dos pais. Já na escola, esse tempo de leitura é menor porque o professor tem que dar contas de outros conteúdos. Sendo assim, percebe-se que:

Dentro do seio familiar a leitura é mais leve, prazerosa, criando um vínculo maior entre pais e filhos, num primeiro momento com a observação das ilustrações, dos livros lidos pelos pais, com a audição de cantigas de ninar, de histórias para dormir, de que a criança se sinta com vontade de retribuir e contar ou ler suas próprias histórias (RAIMUNDO, 2007, p. 111).

A leitura no ambiente familiar, concomitantemente, os níveis de leitura (sensorial, emocional e racional) estarão presentes, especialmente a sensorial porque é mais rápida, irracional e ingênua, pois:

O nível sensorial é muito rico para ser explorado no contexto familiar, desde a gestação do bebê, a mãe ao embalar a criança com canções de ninar já estimula o gesto pela leitura. Por que não é somente o impresso, mas a música, os desenhos todos são modos de leituras que podem ser trabalhadas em família no aconchego do lar (VIEIRA, 2004, p. 3).

O ambiente informal, neste caso a família é o lugar onde a leitura sensorial é desenvolvida, pois a criança começa a se interessar pela leitura e, contudo, os outros níveis de leitura (emocional e racional), aos poucos, vão sendo desenvolvidos e:

Os pais podem iniciar contando histórias para os filhos dormirem, presentear as crianças com livros, incentivar os filhos a contarem histórias em casa, assim haverá sempre uma troca de conhecimentos e cria-se um estímulo para que as crianças, adolescentes e jovens tenham realmente prazer pela leitura, pois não adianta crianças crescerem ao redor de livros e odiarem a leitura (Ibid, 2004, p. 05).

O indivíduo que tem no seu ambiente familiar material de leitura e os usa, está sempre estimulando a desenvolver o gosto pela leitura, pois os jornais, as revistas, os livros de receitas, os livros literários, entre outros, motivam e oportunizam a interação entre o texto e o leitor em formação, e a leitura passará a ser ferramenta para o conhecimento de mundo, tanto o mundo fantástico, como o mundo real e social, dessa forma:

Utilizamos a leitura em vários locais e com diversas finalidades em nossas vidas: no trabalho, na escola, no lazer ou em casa. E "a leitura em casa está ligada ao lazer enquanto em outros ambientes formais e estruturalmente rígidos, ela é utilizada como meio de acesso à informação e formação de uma visão de mundo" (VIEIRA, 2004, p.4).

A formação do leitor se inicia na família e conta com mediadores que são os professores na escola, e dessa forma, a depender do ambiente, a leitura tem utilização diferenciada. 


\section{A ESCOLA E A LEITURA}

A escola é vista como espaço social e cultural de grande relevância para a humanização das gerações mais jovens, em que é preciso inclui-los nos bens de conhecimentos discursivos e simbólicos. Os bens de conhecimentos a que esses jovens são impostos pela sociedade, os habita a descrever e modificar numa cumplicidade o inevitável, e "a escola é um lugar aristocrático para construção da cidadania e para a formação e mudança do indivíduo que nela está envolvido, com maior relevância, os professores e alunos" (PULLIN e MOREIRA, 2008, p. 232).

A leitura tem relevância de grande proporção na vida do estudante e contribui consideravelmente para formação do indivíduo, inspirando-o nas diversas formas de se encarar a vida, e assim desenvolvendo a capacidade cognitiva de cada ser e indispensável à vida sociocultural.

A aptidão pode ser construída com base em práticas particulares e estruturada aos componentes curriculares da escola e presentes nas práticas docentes do seu cotidiano nos segmentos de ensino. A leitura não é só uma das ferramentas mais importantes para o estudo e o trabalho, é um instrumento muito prazeroso à vida, pois a leitura é conhecimento essencial para o ser humano, pois:

Tornou-se hoje, portanto, uma ferramenta indispensável à vida em sociedade, mesmo que não levemos conta qualquer preocupação cultural mesmo havendo outras formas de acesso ao patrimônio cultural, graças às técnicas audiovisuais, ler continua sendo a ferramenta privilegiada de enriquecimento pessoal (MARTINS, 2004, p. 67).

O papel da escola na formação do leitor é repensar suas práticas leitoras, revisando seu Projeto político Pedagógico e, acima de tudo, as práticas docentes devem estar atualizadas para que possa acompanhar o alunado de forma eficaz e dinâmica, não deixando que o início prejudique o fim, por que:

Se algumas metodologias e estratégias propostas para o desenvolvimento da leitura parecem enganosas por trilharem caminhos equivocados, o engano instaurou-se no começo do caminho, a partir do diagnóstico do declínio ou da inexistência do hábito de leitura entre os jovens (LAJOLO, 2004, p. 107).

O professor será, sem dúvida, o grande responsável pela busca de estratégias de leitura que melhor atenda aos alunos, e a sua ação alicerçará o processo de formação de leitores para que o gosto pela leitura aconteça. A escola precisa mobilizar seus alunos para compreenderem a leitura como elemento desafiador e que pode ser 
conquistado plenamente, dando autonomia e independência aos mesmos, pois um indivíduo letrado está preparado para um mundo melhor e cheios de opções.

Os livros nos transportam para o mundo e dessa forma a escola deve se encarregar de formar leitores e não apenas com o aprendizado da leitura com fins para escrita, e "a leitura é fundamental para que a pessoa desenvolva o raciocínio, sua capacidade de pensar e argumentar" (SOUZA, 2009, p. 07).

A leitura não é atividade auxiliar da escrita, sendo assim, deve caminhar junto, e os professores devem rever suas práticas, caso contrário os problemas com a leitura estarão sempre influenciando de forma negativa na aprendizagem do aluno. Isto é fato nos resultados das avaliações externas e na compreensão de mundo "para suprir as carências na formação de leitores, será necessário que muitas vezes a escola deixe de lado a preocupação com o ensinar a ler para dar ao estímulo a vontade de ler" (Ibid., 2009, p. 8).

À escola cabe inovar seu repertório de leitura diversificando as atividades escolares trazendo para seu currículo: simpósios, mesas redondas literárias, discussões, comentários acerca do que foi lido. Só desta forma, poderia despertar no aluno, o prazer pela leitura dentro e fora da escola, até porque o aluno precisa nesse contexto informacional de conhecimento, saber como escolher o que deseja ler, e:

Cabe ao professor promover no espaço de aula, um espaço Interativo, participativo e tentar extrair dos discentes o conhecimento tácito que estes têm para enriquecimento da discussão, uma vez que diversificadas são as multirreferências que compõe cada um (SOUZA, 2009, p. 06).

O aluno deve ser respeitado de acordo com suas origens, para que haja um planejamento humanizador e justo, nas indicações dos livros e das atividades, onde o leitor seja motivado pelo prazer de ler e de fazer suas escolhas, sentindo-se bem e satisfeito para ler, e que essa leitura o leve ao desenvolvimento da crítica, da argumentação, mas que seja apreciada com interesse, para que o aluno se sinta estimulado à leitura de diferentes textos.

Os alunos de escolas públicas em sua maioria não gostam de ler e encontram outras formas de preencher seu tempo fora da comunidade escolar. Como resolver o desinteresse do aluno para leitura? Como lidar com a falta de interesses por textos literários? Os Parâmetros Curriculares Nacionais assumem o impasse apresentado ao ensino de literatura a existência de um espaço entre leitor e obra literária, pois:

Fechado, um livro é literal e geometricamente um volume, uma coisa entre outra. Quando um livro é aberto e se encontra com seu leitor, e então ocorre 
o fato estético. Deve-se acrescentar que um mesmo livro muda em relação a um mesmo leitor, já que mudamos tanto (BRASIL, 2001, p. 65).

A leitura de um livro é como um encantamento, o livro escolhe o leitor, que por sua vez encontra nesse texto o prazer de ler, em consonância com essas ideias busca extrair as várias interpretações, pois expõe ideias, conceitos e compreensões. Portanto de acordo com o ponto de vista de cada leitor, tem a importância fundamental na preparação para desenvolver com sucesso o processo de ensino/aprendizagem da leitura, que prevalece o objetivo de trabalhar com conhecimentos leitores.

Os alunos precisam aplicar em suas atividades escolares e em suas vidas, os conhecimentos aprendidos visando mostrar de forma reflexiva, o funcionamento da língua e a pensar sobre ela, até porque a leitura de um livro contribui para a melhoria das aulas de língua portuguesa e porque não dizer, para melhoria da educação em nosso país.

\section{O TEXTO LITERÁRIO}

As leituras de uma obra literária são irrefreáveis e diferenciadas dependendo do contexto em que são colocadas e cabe ao professor e a escola mediar essa leitura, pois a linguagem é variável em contextos específicos, um texto literário não se basta com uma interpretação, pois sua linguagem é diversa e atende a todos os propósitos em diferentes situações, até porque, sendo a linguagem única, cada leitura está historicamente situada.

A linguagem literária é um artefato das escolhas feitas pelo seu próprio autor, como à gramática, às referências de tempo, espaço, as lacunas deixadas no texto para aguçar o leitor a interpretação, a leitura constitui-se num entendimento, numa interpretação que se realiza por partes, sendo predeterminado culturalmente, de modo que existem interpretações mais e menos adequadas.

A linguagem de um texto literário é diversificada, e, por conseguinte, explana uma consciência singular da realidade, mais não é realidade é fiç̧ão, pois, "um enunciado é fictício quando ele não pode ser corrigido pela realidade, mas criticado interpretado" (HANSEN, 2005, p. 14). Desse modo, para se fazer a leitura de um texto literário, compete ao leitor atualizar o que percebe compreender e extrair do próprio texto.

O espaço escolar tem um papel fundamental para formação do leitor literário, sendo essencial que os alunos sejam instruídos a distinguir procedimentos formais e 
estilísticos de um texto literário, para que, dessa maneira possa entrar no universo ficcional e se tornar um leitor ideal desejado para obra em questão, pois:

Uma leitura para se especificar com a leitura literária é consensual que o leitor deva ser capaz de ocupar a posição semiótica de destinatário do texto, refazendo os processos autorais de invenção que produzem o efeito de fingimento, o leitor deve coincidir com o destinatário do texto para receber a informação de modo adequado (HANSEN, 2005, p. 14).

Os alunos precisam alargar um gosto literário partindo das regras de estilos que se tem em um texto literário, para que aprecie a leitura é preciso que o espaço escolar aplique práticas pedagógicas diferenciadas e sendo assim, tornar-se um mediador na realização de pertencimento de significados. Ao abordar sobre os valores sociais, elucida-se que:

A conquista da leitura é o primeiro passo para a formação dos valores da sociedade, propiciando a participação social, compreensão do homem pelo homem, nível cultural, forma de lazer, formação e exercício da cidadania, inclusão e acessibilidade. A formação do leitor envolve os aspectos políticos, psicológico e metodológico por meio das ações de leitura, considerada como processo constante de esforços conscientes da área educacional, em um contexto em que o professor e o bibliotecário sejam agentes de inclusão social e informacional através da mediação da leitura (MORO e ESTABEL, 2012, p. 58).

O espaço escolar é uma instituição autorizada e legitimada em toda sociedade, onde os alunos podem ter acesso a todos os tipos de textos literários, os projetos de leitura dentro e fora do espaço escolar devem ser aceitos e validados pela instituição formadora de leitores, pois se constituem como prática para desenvolver os textos propostos, de forma que despertem a criação e produção intelectual do leitor e da obra.

A leitura não pode ser limitada aos livros didáticos ou a aulas com foco em leitura literária, mais de vários textos que agucem o leitor a criticá-los e relacioná-los com o conhecimento de leitura e o texto lido, de maneira que, o leitor se posicione ante a obra, assim como afirma os PCN, os professores precisam encontrar formas que extrapolem o uso do livro didático, que envolvam escolhas da escola, do professor.

As atividades a serem desenvolvidas devem estar em consonância com o sócio econômico e cultural do aluno envolvendo os textos literários (formais) e orientar o conteúdo, mas essa não é a única função da escola pois hoje em dia a escola deve possibilitar formas de acesso ao lazer, a cultura, as práticas esportivas, permitindo a agregação mais eficiente dos alunos na sociedade, pois: 
O desafio social da leitura detém, como nódulo central, a habilidade da contra leitura, porque é com ela que podemos, com base na habilidade de brandir a autoridade do argumento, não só ir além do argumento, mas principalmente cultivar o saber pensar para melhor intervir. Ler significa tanto compreender significados quanto atribuir significados alternativos ao mundo, emergindo 0 leitor/autor (DEMO, 2007, p.23).

Professores, profissionais da educação, pedagogos e comunidade escolar precisam estar seriamente cientes da importância da leitura literária e dos livros para a vida individual, social e cultural dos sujeitos, devendo, portanto, executar a tarefa de ensinar a ler, com maior severidade possível e ainda com caráter inovador, enfocando que, o desinteresse pela leitura está associado a falta de estímulos das propostas oferecidas pela escola. Diante desta abordagem afirma-se que:

Partilhar é um termo ideal, porque antes de tudo, leitura é uma experiência
que envolve a troca, o diálogo e a interação. Muito se ouve fala que os alunos
não leem. Há uma questão, no entanto, que deve anteceder a essa: Como o
professor enfrenta o desafio da leitura? Nesse sentido, o professor que deseja
formar leitores e promover em sala de aula precisa se perguntar antes: Como
me tornei leitor? Como descobrir o interesse pela leitura? Qual a experiência
de leitura que eu tenho que partilhar com os outros? (GRAZIOLI e COENGA,
2014, p. 191).

Os textos são oferecidos sem objetivos concretos e funções reais de contextualização com a realidade do aluno, sendo esse o motivo que afasta o aluno da aula de leitura, como também o material a ser oferecido para aula de leitura deve ser selecionado anteriormente, para que se tenha uma contribuição prévia e informações sobre o texto.

Na leitura informativa, o texto dará dados específicos para uma pesquisa sobre fatos da atualidade que nesse caso, teremos o cunho pedagógico para adotar uma atitude estratégica de aprendizagem de leitura, que fará com que o professor e aluno estabeleçam uma relação de interação para compreenderem a riqueza do universo leitor. Pois, criando um espaço de confiança, constroem-se opiniões críticas em busca do conhecimento e sabedoria da liberdade com maturidade, e neste sentido, há diversas formas de mediação que podem ser feitas pelo professor. Vale salientar que:

Para formar um leitor crítico e sensível, capaz de compreender e interpretar aquilo que lê, de construir significados e transformá-los em palavras, exigese do mediador de leitura uma intervenção adequada, contínua e explicita, que precisa ocorrer de forma consciente e sistemática antes, durante e depois das atividades de leitura (LUFT, 2012, p. 163).

O saber é liberdade com responsabilidade, e o professor deve passar isso para o aluno de forma segura e convincente, pois ler é estar em todo lugar o tempo todo para encantar e ser encantado; entender e ser entendido, porque quem ler tem 
possibilidades de compreender o mundo de maneira universal. Faz-se necessário lembrar que os educadores são a voz que canta, a mão que "abre portas e traça caminhos entre a alma dos textos e a alma dos leitores. Seu trabalho com literatura é risco e incerteza" (REYES, 2012, [s/p]).

A leitura está em tudo, numa figura, em dicionários, manual de funções, frases em ônibus, caminhões, nas pessoas, e outros, pois quando os alunos não estão na escola leem decididamente, só não se dão conta disso, e dizem não saber ler, porque têm medo de errar e os colegas o chatearem com apelidos e rótulos desagradáveis.

A leitura obrigatória na escola não é de toda negativa, pois existem alunos que, a partir de textos lidos na escola, desperta o prazer de ler e se interessam por outros livros, por livre e espontânea vontade, solicitando o livro lido na aula e outras obras e até mesmo outros autores os quais lhe tocam por qualquer motivo. Quando nos deparamos com tal situação, devemos aproveitar a oportunidade e incentivá-lo a saciar a sua vontade de ler e abordar a importância do diálogo entre o autor e o leitor, por que:

\begin{abstract}
Para que um texto tome vida, há de que o leitor não só reconheça as informações pontuais nele presente, mas que aprenda quais sentidos forma produzidos por quem as escreveu. Levantar hipóteses e produzir inferências antecipe aos ditos no texto e relacione elementos diversos, presente no mesmo ou que façam parte de suas vivências como leitor (PULLIN e MOREIRA, 2008, p. 35).
\end{abstract}

Ao proceder assim, o leitor compreenderá as informações ou interrelações entre informações que não estejam explicitas pelo autor do texto. Por isso, a leitura é uma produção: a construção de sentido se atrela a realização de pelo menos esses processos, por parte do leitor. A compreensão do texto lido é resultante dessas produções: prévias, por parte de quem as escreveu, e das que ocorrem ao ler, por parte do leitor.

Ler é um ato libertador, a busca do livro deve ser feita pela espontaneidade, pela alegria de fazê-lo, e encaminhar-se para explorar potencialidades do homem, para que se desperte a leitura, não basta que se ofereça ao aluno aulas esporádicas de leitura, mais dar oportunidades de contato com livros o tempo todo.

A escola precisa disponibilizar mais tempo para leitura, porque através da leitura que se resgata o relacionamento profundo com o texto e com o mundo, porque o ensino da leitura deve ser ressignificado pela intervenção mediadora do professor para a formação de um sujeito/autor, em lugar de uma prática de socorro rápido, ou de educação acelerada. Mas isso terá mais sentido se o professor considerar e levar 
para sua prática pedagógica que a leitura é um processo e requer empenho, dedicação e tempo.

\section{CONSIDERAÇÕES FINAIS}

Se nas famílias a leitura é exercitada de maneira acanhada, se o espaço escolar é muito pouco ou quase nada envolvido com a formação do aluno leitor, se quase não temos bibliotecas públicas, faz-se necessário procurar possibilidades que encorajem o avanço desse leitor para que, seja competente no uso da Língua Portuguesa oferecendo oportunidades ao mesmo para expressar seus sentimentos e ideais.

Formar leitores não é um trabalho fácil, e é dever da escola e dos grupos sociais, motivarem a prática da leitura como um instrumento de libertação e de aperfeiçoamento do ser humano. Portanto, as unidades escolares poderiam melhor contribuir com o uso de estratégias e técnicas educacionais criativas e eficientes que induza o aluno. $O$ interesse pela leitura de maneira sólida e segura, motivando-o a fazê-la dentro e fora do espaço escolar com autonomia, criatividade e confiança em si próprio.

Os pais também devem participar de práticas leitoras, mesmo que essas contribuam pouco, é importante para criança ou o adolescente ouvir e ser ouvido, ou admirado pela família, pois isso o incentiva a continuar sua caminhada leitora. A leitura estimulada pelos pais em casa deve acontecer desde a gestação, com contação de histórias, porque é nessa fase inicial da vida que se dá a prévia formação do ouvinte que mais tarde será um bom observador e futuramente um bom leitor.

Os pais e professores exercem um papel de fundamental importância para desenvolver a leitura buscando instigar, deslumbrar, encantar, despertar e convencer esse leitor através de recursos, como: a observação do texto, das ilustrações, da cor, do formato, do cheiro e outros, estimulando os canais sensoriais do leitor.

A leitura e a formação do leitor na escola pública sempre foi e será uma incumbência complexa para professores, pois despertá-los para prática leitora será vencer todas as dificuldades das classes dominadas desses espaços escolares, onde os recursos são poucos ou quase nada. Entretanto a necessidade de ampliarmos o universo de leitores ativos está intimamente ligada a medidas que envolvam o estado e a sociedade, até porque a leitura deverá ser sempre um meio e nunca um fim.

\section{REFERÊNCIAS:}


BORGES, C. J. Educação física para o pré-escolar. Rio de Janeiro. Sprint. 1987

BRASIL. Parâmetros Curriculares Nacionais. 3. ed. Brasília: MEC, 2001.

CHARMEUX, E. Aprender a ler: vivendo o fracasso. S P: Cortez. 1994.

COLOMER, T.; CAMPS, A. Ensinar a ler, ensinar a compreender. Tradução de Fátima Murad. Porto Alegre: Artmed, 2002.

DEMO, O. O porvir: desafio da linguagem do século XXI. Curitiba, PR: Ibepex. 2007.

GRAZIOLI, F. T. COENGA, R. E. Literatura infanto juvenil e literatura: novas dimensões e configurações. Erechim: Habilis, 2014.

HANSEN, J. A. Reorientação no campo da leitura literária. In: ABREU. M.; SCHAPOCHNIK, N. Cultura letrada no Brasil: objetos e práticas. Campinas: Mercado de letras. ALB: São Paulo: Fapesp, 2005.

LAJOLO, M. Do mundo da leitura para leitura do mundo. 6. Ed. São Paulo: Ática, 2004.

LIMA, E. S. Currículo e desenvolvimento humano. In: BEAUCHAMP, J. et. Al. (Orgs) Indagações sobre o currículo. Brasília. Secretaria de Educação Básica, 2008.

LUFT, G. F. C. Práticas leitoras Multimídias e formação de leitores: a leitura como ato criativo, participativo e dialógico. In: NEVES, I. C. B.; MORO, E. L. S.: ESTABEL, L. B. (Org). Mediadores de leitura na bibliodiversidade. Porto Alegre: Evangraf, 2012.

MARTINS, M. H. O que é leitura. 8 ed. São Paulo: Brasiliense, 1988.

MARTINS, M. L. R. A problematização como prática pedagógica. São Paulo: Anais da III CBE, 2004.

MORO, E. L. S. ESTABEL, L. B. Mediadores de leitura na bibliodiversidade. Porto Alegre: Evangraf, 2012.

PULIN, E. M. M.P. MOREIRA, L. S. G.. Prescrição de leitura escola e formação de leitores. Revista Ciência e Cognição, vol 13. 2008.

RAIMUNDO A. P. P. A mediação na formação do leitor. In: CELLI - Colóquio De Estudos Linguísticos e Literários, n3. 2007.

RANGEL, E. O.; ROJO, R. H. R. Língua Portuguesa. Brasília: Ministério da Educação, Secretaria de Educação Básica, 2010.

REYES, Y. Ler e brincar, tecer e cantar: literatura, escrita e educação. Pulo do Gato, São Paulo: 2012. 
ROCCO, M. T. F. A importância da leitura na sociedade contemporânea e o papel da escola nesse contexto, 2013.

SOUZA A. L. B. M. A importância da leitura para a formação de uma sociedade consciente. Revista UNIRB [online], , v. 1, n. 2. Salvador 2009.

VIEIRA, R. A.: FERREIRA, R. M. N.: SCHMIDLIN, R. F. M. Seminário Biblioteca Escolarl II: espaço de ação pedagógica. Escola de Ciência de Informação da Belo Horizonte. 2004. 